\title{
¿Hacia una renovación de la Historia? Post-apocalipsis, ideología y lengua en Mecanoscrito del segundo origen de Manuel de Pedrolo ${ }^{1}$
}

\author{
Towards a History renewal? Post-apocalypse, ideology \\ and language in Manuel de Pedrolo's \\ Typescript of the second origin
}

\author{
Alfons Gregori \\ Uniwersytet im. Adama Mickiewicza w Poznaniu \\ alfons@amu.edu.pl
}

\begin{abstract}
The aim of the present paper is to determine several fissures and inconsistencies leading to unsolvable ambiguities of meaning in Manuel de Pedrolo's novel Typescript of the second origin by means of a critical analysing of its linguistic and ideological issues, specially its religious groundwork - which is both stylistic and related to ideological content. However, some elements weaken the narrative's disrupting character, making almost inevitably the failure of this revolution, as it is evidenced in the epilogue. In short, Predolo's novel may be interpreted as a strong claim against History.
\end{abstract}

Keywords: Contemporary Catalan literature, ideology in literature, literary language, post-apocalyptical fiction, dystopian fiction, Manuel de Pedrolo

\footnotetext{
${ }^{1}$ Quisiera dedicar el presente artículo a Pedro Nilsson-Fernàndez, que activó en mí la "señal de alerta" respecto a la novela de Pedrolo. Cabe apuntar que una versión reducida de este trabajo fue presentada en la Jornada Universitària Manuel de Pedrolo, contra l'oblit de l'escriptor modern, organizada en la Universitat Pompeu Fabra el 15 de mayo de 2014, y, ya en un formato más cercano al definitivo, en una ponencia ante el Grupo de investigación sobre lengua, cultura e identidad en la era global de la Universitat Oberta de Catalunya, el 28 de abril de 2015.
} 


\section{INTRODUCCIÓN}

Mecanoscrit del segon origen (1974) es el título original del long-seller más importante de la literatura catalana, traducido a una gran variedad de idiomas, ${ }^{2}$ y por eso mismo una novela sobre la cual se han emitido multitud de comentarios y opiniones. Sin embargo, a decir verdad, existen escasos trabajos académicos que profundicen en la red de elementos temáticos, estilísticos, genéricos y narratológicos que la conforman no solo como una obra cuya lectura se pretende fluida y su orientación revolucionaria, sino sobre todo como un relato con fisuras, brechas de sentido, disensiones y contradicciones. ${ }^{3}$ Un hecho de gran relevancia en todo ello, y muy cuestionable, fue circunscribirlo al ámbito de la literatura juvenil (o young adult fiction), aunque eso mismo lo llevó a ser lectura de cientos de miles de jóvenes catalanohablantes. ${ }^{4}$ En efecto, a medida que se iba instaurando un modelo de enseñanza en que la lengua vehicular pasaba a ser mayormente el catalán, Mecanoscrito del segundo origen se convirtió en una de las obras más populares en los centros de secundaria. Determinados factores contribuyeron a encasillarla como novela juvenil, aunque por separado ninguno puede determinar dicha etiqueta: sus protagonistas eran dos adolescentes, la primera edición salió en la colección juvenil El Trapezi y se trataba de un género en la órbita de la ciencia ficción. ${ }^{5}$

Si bien es cierto que el reciente revival de qué ha gozado en 2018 el escritor en el marco de las conmemoraciones del Any Pedrolo ha tenido un marcado acento

\footnotetext{
${ }^{2}$ En el momento de escritura de este artículo se constata su traducción a trece idiomas: neerlandés, euskera, gallego, francés, rumano, portugués, italiano, búlgaro, esloveno, bretón, macedonio, inglés y dos versiones en castellano. Al ser este un trabajo en español, el título de la obra se mencionará en la formulación coincidente de estas dos últimas, es decir Mecanoscrito del segundo origen. Sin embargo, siendo un artículo académico, se citará el original en lengua catalana.

${ }^{3}$ Recientemente ha venido a cubrir dicho déficit un volumen íntegramente dedicado a la novela de Pedrolo, Explorant Mecanoscrit del segon origen: noves lectures (2018), editado por la experta en ciencia ficción Sara Martín Alegre. Los textos proceden de un monográfico en inglés de la revista en línea Alambique (v. Martín Alegre, 2017). Dicha investigadora se encargó también de la traducción de la novela a esta lengua, bajo el título Typescript of the second origin (v. Pedrolo, 2018), en un paso más para su difusión internacional. Cabe mencionar, igualmente, que Martín Alegre es la responsable de una edición trilingüe de la novela de carácter institucional (v. Pedrolo, 2016), publicada a raíz de la celebración en Barcelona de la Eurocon, la convención europea de ciencia ficción y fantasía.

${ }^{4}$ La popularidad de la obra aumentó a mediados de los 80 con la adaptación de la novela en formato de serie, que emitió la televisión pública catalana, y con su dramatización en Catalunya Ràdio. En cambio, la película producida recientemente bajo el título de Second Origin (2015), un antiguo proyecto de Bigas Luna que no convenció a Pedrolo, ha sufrido un rotundo fracaso por diversos motivos que exigirían una explicación más pormenorizada.

${ }^{5}$ Especialmente si tenemos en cuenta, como afirma Munné-Jordà (2006), que la definición de El Trapezi como colección juvenil era solo formal, ya que incluía, entre otras obras, Mamb de Gorki, The Man Who Was Thursday de Chesterton y The Day of the Triffids de Wyndham.
} 
ideológico, ${ }^{6}$ todavía queda trabajo por hacer al respecto en el ámbito académico. La obra se mueve en un terreno bastante complejo, siendo conveniente estudiarla como muestra de literatura post-apocalíptica que plantea una nueva etapa histórica u otra Historia. Muchos lectores observaron un cierto paralelismo entre el intento de reconstrucción coetánea de una catalanidad herida de muerte y el argumento de la novela, que se resume en el intento de Alba y Dídac, de 14 y 9 años de edad, respectivamente, de seguir adelante tras un ataque alienígena, mediante la lucha cotidiana por la supervivencia y la búsqueda de una concordia ética para la convivencia. En ese momento de franquismo agonizante, ${ }^{7}$ si bien con muchos claroscuros en el horizonte, sectores comprometidos de la sociedad buscaban los valores democráticos que le servirían de base para abandonar la castración intelectual, económica y moral que ejercía el régimen. ${ }^{8}$ No obstante, existen argumentos de peso que plantean dudas sobre la viabilidad de lecturas -hasta cierto punto superficiales o estereotipadas- que sean fruto de analogías con los hechos históricos y el ambiente sociocultural que vivió Pedrolo, entre otros motivos porque a menudo no han tenido en cuenta el aspecto formal y constitutivo de la novela. En este marco, el objetivo del presente trabajo consiste en determinar diversas fracturas e incongruencias que aportan ambigüedad y riqueza al texto, mediante el análisis crítico de cuestiones lingüísticas, ideológicas y temáticas presentes en el mismo.

\section{LA LENGUA LITERARIA: MÁS ALLÁ DE UNA APARENTE SENCILLEZ}

Recordemos rápidamente la estructura de la novela, que está estrechamente ligada a las cuestiones planteadas, en especial aquella con que se va a iniciar el análisis: la influencia del artificio de la lengua en la configuración de la obra, un aspecto que ha sido poco tratado. La novela se divide en dos partes: por un lado, un supuesto mecanoscrito conformado por cinco capítulos denominados "cuadernos", y, por el otro, un breve epílogo redactado por el editor anónimo del mecanoscrito. Hablando de

\footnotetext{
${ }^{6}$ Lo ejemplifican tanto los estudios académicos - p.ej. la cuasi totalidad de artículos que forman el monográfico editado por Martín Alegre $(2017 ; 2018)$ inciden en aspectos ideológicos más o menos controvertidos de la novela- como las apologías de carácter reivindicativo que se realizan del autor desde el entorno de la izquierda independentista, como se constata en la siguiente afirmación de Bennassar (2013): “[...] Pedrolo es va convertir en algú molest per al nou règim polític governant, una dreta burgesa a la qual atacava constantment des dels seus posicionaments ideològics: l'alliberament nacional, l'alliberament de classe, l'alliberament de la dona".

${ }^{7}$ Pedrolo inició la escritura de la novela en 1973 (Martín Alegre, 2018a, p. 18).

${ }^{8}$ Maestre Brotons (2018) recurre a los planteamientos de la contracultura para explicar la base ideológica que Pedrolo confirió a la novela aquí analizada. Otra línea de estudio sería la que podría desarrollarse a partir del poso ácrata de la obra, que no sin ironía apuntó Hernández Ripoll (2001), o focalizando en su carácter libertario, como Martín Alegre (2018b, p. 161).
} 
artificios, el relato se inicia en Benaura, el único topónimo inventado del texto, que ha sido identificado con Tárrega. Al parecer de origen árabe por su morfología, con él queda manifiesta la pluralidad de salida de la cultura catalana, ${ }^{9}$ a pesar de que este adjetivo identitario no se explicite en el texto, contribuyendo al aura universalizante del mismo. En esta línea, podemos suponer que el hecho de vivir en esa Cataluña interior ficcionalizada garantizaba que la lengua de Alba y Dídac fuera en primera instancia el catalán, por tanto la lengua previsible para el futuro de la humanidad. ${ }^{10}$ ¿Era esta universalización del relato meramente una medida para esquivar la censura?

A la hora de abordar la cuestión formal, en primer lugar habría que analizar el modelo estilístico y los registros empleados en la novela, discerniéndola como construcción literaria. Cabe destacar que el léxico de la voz narrativa se diferencia claramente del que domina en los diálogos entre los protagonistas. Así, los personajes de Alba y Dídac hablan con una lengua neutralizada, sin una estilización marcada ni localismos, siendo un modelo lingüístico con el que muchos jóvenes podían sentirse identificados en grandes ciudades de la Cataluña coetánea como Barcelona -aunque les debía sorprender la ausencia de castellanismos. En cambio, la voz narrativa emplea numerosas formas elevadas o específicas de la lengua literaria catalana, que podrían representar muestras diatópicas o diacrónicas del catalán, como las siguientes (citadas de acuerdo con el paginado de Pedrolo [1984]):

Conjunciones/locuciones conjuntivas: "car" (33, 43, 49, 91, 92, 94), "puix que" (40, 49, $62,87,100,112,128,132,139,149,157,164)$, "atès que" $(126,153)$.

Locuciones prepositivas: "a despit de" (39, 139), "a desgrat de" (119).

Verbos: "enllorar-se" $(53,115)$, "llanguir" (55), "enquimerar-se" (55, 58, 90, 164), "sebollir" (67), "conjuminar" (95), "adollar-se" (115), "enardir-se" (116), "llostrejar" (132), "pouar" (139), "lascerar" [lacerar] (149).

Substantivos: "atuells" (42, 113), "estolidesa" (65), "encontorns" (68, 80, 144), "herbei" (73), "celístia" (78), "requisa" (99), "beutat" (121), "desbocament" (121), "sina" $(125,151)$, "glapit" (132), "besades" (143), "miasmes" (153), "cobricel" (154).

Adjetivos: "llur,-s" (por doquier), "qualque" (34, 91), "putrificable" (73), "recanciosos" [recançosos] (105), "migdial" $(114,132)$, "intocades" (123), "imposant" (124), "folla" (126), "enfurida" (128), "aqueferat" (140), "llangorós" (151).

Fraseologismos: "tinguessin lleure de" (83).

Una de las frases representativas de dicho registro es la siguiente: "Ara, aquells glapits ho desmentien, si verament eren de ca" (132). ${ }^{11}$

${ }^{9}$ Dídac, además, es de raza mixta.

${ }^{10}$ Cada vez que la voz narrativa se refiere a la lengua empleada recurre a la expresión "su lengua". Solo cuando contemplan las consecuencias de un desprendimiento de rocas en Montserrat, momento en que se sienten "[...] més petits que mai" (Pedrolo, 1984, p. 76), podría haber una sutil referencia a la implicación textual de un símbolo nacional catalán.

${ }^{11}$ Todo ello desmiente de forma categórica la afirmación del autor según la cual su labor consistió en elaborar un texto que diera la impresión de haber sido escrito por una adolescente (García, 1997; citado en Nilsson-Fernàndez, 2018, p. 110). 
Además, se introduce una terminología científica que, a mediados de los años setenta, disponía de menos difusión en catalán que hoy en día: "fetus", "impregnació", "gens rescissius" [recessiu] (141), "espèculum" (145). Se trata de términos de la ginecología, la obstetricia y la genética que tienen mucho que ver con la voluntad de la pareja protagonista de reproducirse, garantizando así la pervivencia de la humanidad. La voz narrativa emplea en pocas ocasiones formas de la variante noroccidental de la zona de Tárrega, como "remijó" (42) o "feia una mica de quimera" (123). En la mayoría de estos usos lingüísticos se percibe la marca didactista de Pedrolo, que deseaba hacer frente a una situación de la lengua catalana considerada catastrófica, tras siglos de represión, falta de instrucción en la lengua propia y la entrada vigorosa de argot juvenil español en el tardofranquismo. El autor seguramente intentaba enriquecer el vocabulario de los jóvenes y no tan jóvenes, contribuyendo así a la reconstrucción de la cultura nacional. Al mismo tiempo, la combinación de este registro con el modelo neutralizado de los personajes, reconocible para la mayoría de hablantes, permitía un relativo acercamiento de los lectores al texto, que además llegaba a su mercado objetivo con el atractivo "envoltorio" de la ciencia ficción.

Por otro lado, para un análisis más completo de la lengua literaria empleada en la novela, deben tenerse en cuenta algunos aspectos que la acercan a la tradición religiosa. De este modo, el tono medido e incisivo, sentencioso, que vamos encontrando, así como una enunciación distanciada del narrador y bastantes descripciones de acciones cotidianas sugiriendo trascendencia procuran evocar las Escrituras, en especial los textos neotestamentarios. Además el mecanoscrito aparece distribuido en fragmentos que, al iniciarse con la conjunción " $y$ ", recuerdan la división en versículos, mientras que el epíteto referido a Alba que se repite al principio de cada cuaderno confiere un cierto carácter legendario o mítico a la narración. Todo ello indica la formulación imitativa de textos con propósito evangelizador.

\section{LA TRANSGRESIÓN IDEOLÓGICA: MÁS ALLÁ DE LOS LUGARES COMUNES}

Estos rasgos constitutivos de Mecanoscrito del segundo origen como artefacto literario están estrechamente relacionados con la dimensión transgresiva del texto, que torpedea las estructuras socioculturales occidentales: tanto a nivel estructural como mediante alusiones concretas, se observa una serie de referencias a la tradición religiosa y elementos culturales que parten de la Biblia, formando una red de paralelismos antagónicos a las Escrituras. Desde esta perspectiva Alba y Dídac serían una especie de anti-Adán y Eva, ${ }^{12}$ y Benaura un Edén trasmudado, donde hay maldad

\footnotetext{
${ }^{12}$ Bensoussan (1988, p. 78) ya detectó esta transgresión en concreto y la consideró una inversión del mito.
} 
pero no expulsiones: los protagonistas se van de Benaura porque quieren, nadie les echa. En ello entraría el simbolismo del agua, los mitos de la destrucción (el arca de Noé, el episodio de Sodoma y Gomorra), o el epíteto de Alba. Este, p.ej., la elevaría sobre su posición de persona de carne y huesos, pero distanciándose del referente cristiano, ya que -frente al uso más bien estático del epíteto en la antigüedady el medioevo- el epíteto de la muchacha es cambiante, variando en función del paso del tiempo y la evolución de su organismo. ${ }^{13}$

En la novela Alba es la portavoz de una ideología contraria a los valores promulgados por la Iglesia católica como institución anclada en la Historia: el respeto hacia la alteridad (de raza, de ideas), la libertad sexual y el laicismo. ${ }^{14}$ Estos han sido los principios en torno a los cuales ha sido interpretado el nuevo orden civilizatorio que se inaugura en la obra. Ahora bien, ¿son estos los que previsiblemente van a ser transmitidos intergeneracionalmente? Fijémonos que una de las principales decisiones tomada por Alba y secundada por Dídac es salvar el máximo número posible de libros de las bibliotecas en ruinas. $\mathrm{Si}$, por un lado, la acción resulta imprescindible para que la humanidad futura pueda conocer y recordar una cantidad de saber imposible de retener por dos individuos, también es verdad que la mayoría de los volúmenes rescatados transmitirán en varios grados los puntos de vista y las estructuras lógicas del paradigma occidental, es decir, el propio de la tradición patriarcal judeocristiana. En este sentido, la pareja protagonista padece una glorificación acrítica del saber que encaja con una visión ingenua del progreso derivada de la Ilustración. Por otro lado, si "su lengua" es el catalán y se dedican a salvar libros de la Biblioteca de Cataluña y otras de sus alrededores, se supone que este idioma será el principal en la transmisión de conocimientos. ${ }^{15}$

En cualquier caso, la lógica de la transgresión mencionada no se limita a una inversión de elementos míticos. En este sentido, y siguiendo ciertas pistas autoriales, Dídac sería la encarnación invertida de un personaje que, prototípicamente, podría ser designado como el Viernes de Defoe, o sea una figura representativa de otra raza considerada primitiva por los prejuicios racistas predominantes, y por lo tanto subordinada al personaje de Robinson Crusoe. Esta contraposición se debe a que Dídac posee un don innato para la mecánica y la técnica, es decir, una parte substancial de

\footnotetext{
${ }^{13}$ Para un examen detallado del papel del texto bíblico y de su herencia moral y religiosa en Mecanoscrito del segundo origen, v. Gregori (2015).

${ }^{14} \mathrm{~A}$ estos habría que añadir la ética del trabajo y del esfuerzo. Si bien desde Weber ha sido reiteradamente vinculada al progreso del capitalismo en entornos protestantes, sería sin duda complejo escindirla del discurso propio del catolicismo.

${ }^{15}$ Gallardo Torrano (2018, p. 66) plantea una interesante cuestión, al afirmar que el español debía ser la lengua de la gran mayoría de libros que salvan Dídac y Alba, aludiendo de algún modo a las causas: las restricciones impuestas sobre la difusión del catalán y la conservación de obras en esta lengua. No podemos olvidar que, ya a partir del s. XVI, el uso del castellano fue predominante en la producción de textos impresos en los territorios de habla catalana pertenecientes al Reino de España.
} 
aquellos conocimientos y capacidades que convertían al náufrago ficcional no solo en superviviente, sino también en redentor de un mundo post-apocalíptico atrasado que había que civilizar. Sin embargo, paradójicamente, Dídac aparece también como la tabula rasa sobre la cual Alba inscribe aquellos postulados rompedores, que pretenden sustituir el patriarcado y la moral judeocristiana en su globalidad. Esta sustitución es el relato utópico en que se fundamenta la novela: una gran revolución ideológica en un marco distópico poco esperanzador. ${ }^{16}$ En este contexto, Dídac personifica el peón de la trama que tiene que ser "civilizado" a nivel espiritual y ético por su compañera de andanzas, acabando (de nuevo) por representar una persona todavía en fase primitiva, a quien solo la intervención de una blanca bien formada (Alba) puede encaminar hacia un grado superior de humanidad. ${ }^{17}$ Es decir, el supuesto futuro multicultural y arracial que germinaría en la obra estaría limitado por la subordinación de Dídac a Alba.

No en vano la protagonista se comporta en más de una ocasión de un modo altamente paternalista, llegando a ocultar la verdad a su compañero para ahorrarle un sufrimiento que ella considera innecesario, improductivo (cfr. Nilsson-Fernàndez, 2018, pp. 102-103). La chica presenta, pues, dos caras, como si se adaptara al modelo (¿o antimodelo?) de la hipócrita sociedad católica, tan criticada en la obra, por bien que quizás el término "paternalista" debería ser sustituido aquí por el de "maternalista", a causa de la preponderancia que adquiere la mujer como motor de renovación: cuando Alba y Dídac llegan por primera vez a la Benaura en ruinas, los gritos de desesperación de ella van dirigidos a su difunta madre. Frente al orden patriarcal, esta línea matriarcal conectaría con la noción posterior del "orden simbólico de la madre" de Muraro, dirigiendo la cuestión hacia uno de los conceptos más importantes -y polémicos- de la pensadora italiana: la autoridad de la madre. Para Muraro (1994, pp. 102-105), que emplea las bases teóricas del psicoanálisis lacaniano para darle la vuelta, el derecho de la madre es el primer enlace y el primer código de lo que se puede decir (dicibile), ya que las relaciones con la madre pasan por delante de otras instancias del orden social patriarcal. En la novela, el orden simbólico de la madre se vincularía principalmente a la figura de Alba y a su relación con su anhelada descendencia, teórico inicio de un sistema matriarcal.

No obstante, la gran transgresión de la obra reside en la sola solución pertinente ante la ausencia de hombres fértiles y en su sano juicio para procrear con la protagonista una vez fallecido Dídac: el incesto. De hecho, constituye el objeto final de su deseo, que se hace presente al tomar ella la palabra por primera y única vez en el relato. Lévi-Strauss (1969, pp. 41-44, 58-59) identificó la prohibición del incesto con la norma primigenia, fundamental y universal para el surgimiento de la sociedad humana, es decir, con el paso de la naturaleza a la cultura. El hecho de que Alba

\footnotetext{
${ }^{16}$ Martín Alegre (2018b, p. 167) califica el relato de utópico y distópico a la vez.

${ }^{17}$ Para un interesante análisis de la figura de Dídac, v. Martín Alegre (2018b).
} 
haga caso omiso a tal prohibición conlleva una verdadera ruptura respecto a la civilización anterior y la creación de una sociedad humana renovada desde la esencia. Con todo, la inclusión de dicha cuestión en la novela de Pedrolo podría deberse particularmente a una idea que el mismo antropólogo argumentó en su momento: siendo la base de la exogamia en el sistema patriarcal, el incesto es la causa primera del trato de las mujeres como mercancía, al haber impulsado el intercambio de estas entre grupos sociales (Lévi-Strauss, 1969, pp. 65-73). La ruptura del tabú, en consecuencia, supone un ataque a ese sistema, que Pedrolo posiblemente habría identificado no solo con la explotación femenina, sino también con las bases de la explotación capitalista, al reducir lo humano a mero producto económico. ${ }^{18}$ En este sentido, adquiere particular relevancia el último párrafo del mecanoscrito, en el que se descubriría la voz enunciativa del mismo: Alba toma la palabra justo en el momento en el que explicita lo imperioso de llevar a cabo el incesto como condición sine qua non de su cometido, sin muestra alguna de turbación o sentido de la fatalidad. El paso de la heterodiégesis a la homodiégesis comporta un golpe de efecto emocional que contribuye a la legitimación del discurso de la protagonista, quien se revela no solo como una mujer plenamente empoderada, sino también como una excelente constructora de relatos, ubicándose en un plano intermedio entre el del mero narrador y el de la voz autorial. Así, en la estrategia de creación de empatía hacia los personajes se combina la retórica paraevangélica de lo insólito cotidiano, presente en el grueso del mecanoscrito como se ha argumentado en el segundo apartado, y la emocionalidad culminante del último fragmento de los cuadernos.

No obstante, la voz narrativa del epílogo, que nos habla cuando han pasado ya cerca de siete mil años tras la (supuesta) refundación de la humanidad, constata un estado de dominación patriarcal bastante parecido al anterior (el nuestro). Así, las tres personas que monopolizan la transmisión del debate intelectual sobre el mecanoscrito, formando un triángulo cerrado de opiniones y de intereses, son hombres: el erudito Eli Raures, el anticuario Olguen Dalmasas, y el editor del texto. ${ }^{19}$ Este apartado final de la obra es fundamental para indagar en los matices significativos de la misma. Por un lado, recurriendo a una versión renovada del procedimiento del manuscrito encontrado -y de ahí el título de la novela- el epílogo puede ser visto de modo legítimo como un mecanismo propio de la era posmoderna destinado a difuminar las fronteras entre realidad y literatura; asimismo, el editor tiende a validar la "autenticidad" de la obra, tras otorgar más verosimilitud a los argumentos de Dalmasas. Pero observemos más detalladamente este apartado final de la novela: el tal

\footnotetext{
${ }^{18}$ Maestre Brotons (2018, pp. 45-46) alude a Freud a la hora de razonar la ruptura del tabú del incesto en Pedrolo. Sin desmerecer esta opción, los motivos ideológicos arriba referidos y el hecho de que la traducción al español de Las estructuras elementales del parentesco de Lévi-Strauss fuera publicada en 1969 hacen plausible la hipótesis de que la referencia de Pedrolo fuera la obra del antropólogo francés.

${ }^{19}$ Santaulària Capdevila $(2018$, p. 129, 139) llega a la misma conclusión.
} 
Dalmasas es un marchante de antigüedades, es decir, tiene un interés crematístico en aumentar el valor del producto que ha adquirido -representa pues la praxis capitalista- y, obviamente, dicho valor aumenta en la medida que el texto no es una invención literaria, sino que se corresponde con la verdad histórica de un antaño pasado. Al establecer que algunos tabús de su sociedad -aludiendo obviamente al incesto- eran los que impedían aceptar la autenticidad del mecanoscrito y conducían a clasificarlo como mera literatura (Pedrolo, 1984, p. 170), toda esta construcción metanarrativa parece todavía más retorcida. Con todo, la gran paradoja -en contraposición a la gran transgresión antes mencionada- consiste en mantener la autenticidad del texto cuando se hace evidente el fracaso ideológico de la renovación de la Historia gestada en el relato.

En este contexto, Pedrolo estaría lanzando una crítica muy sutil a un determinado discurso falaz que usa de instrumento la historia - en el sentido de disciplina académica y saber objetivado- en relación con la etnografía del mito y el estudio de las creencias. En el ámbito de la exégesis bíblica, se puede hablar de una confrontación histórica (hoy parcialmente superada), entre, por un lado, los creyentes que consideraban las Escrituras un texto literal en su referencialidad y auténtico por su intrínseca condición sobrenatural (como "palabra de Dios") y, por el otro, las tesis que las presentaban como una serie de historias surgidas de la imaginación del ser humano que, a pesar de ciertas coincidencias históricas, debían ser tratadas pragmáticamente como ficcionales y, en consecuencia, se deberían examinar en un marco literario. A grandes rasgos, este debate resultaría análogo al mantenido en el epílogo entre Dalmasas (defensor de la autenticidad y referencialidad del texto) y Raures (valedor de su carácter literario, de ciencia ficción). ${ }^{20}$ El método histórico se aplicó en la exégesis bíblica -especialmente desde las filas del protestantismopara fundamentar su autenticidad referencial, legitimando indirectamente su componente sobrenatural y dotando a la exégesis cristiana de una base científica y racional. ${ }^{21}$ Diversos descubrimientos arqueológicos apoyaron esas tesis, debidamente aliadas de una determinada interpretación de los mismos, de igual modo que los hallazgos realizados en diversas exploraciones espaciales parecen sustentar los postulados de Dalmasas en el epílogo. El problema que plantearía la novela, por tanto, es la peligrosa disposición a mitificar que subyace en el ser humano: como la renova-

\footnotetext{
${ }^{20}$ Claro está que una diferencia notable en la comparación es la ausencia de elementos estrictamente sobrenaturales en el mecanoscrito, otra transgresión de la mano de Pedrolo. No hay que confundir los poderes mágicos e inexplicables de tipo sobrenatural con el componente especulativo de la novela, es decir, la proyección de nuestros conocimientos tecnológicos hacia el futuro con el fin de justificar la capacidad aniquiladora de los extraterrestres.

${ }^{21}$ Como expresa el teólogo Casciaro Ramírez (1983, p. 23), la supresión del método histórico llevaría a un extremo igual de pernicioso que la aplicación radical de este (sin inspiración sobrenatural ni orientación doctrinal): “[...] sería una exégesis espiritualística, sin fundamento científico y racional, con lo cual dejaría de ser scientia y, por tanto, Teología”.
} 
ción de la Historia en realidad había fracasado, la civilización futura era presa fácil de los prejuicios y las mistificaciones derivados de ciertas prácticas hermenéuticas, es decir, se estaba cayendo en los mismos errores que la humanidad previa a la hecatombe. $\mathrm{Y}$ ante ello el único posicionamiento válido es el escepticismo. ${ }^{22}$

\section{CONCLUSIONES}

En suma, la estilización de la prosa del manuscrito no solo debe relacionarse con la popularización de una lengua literaria rica, sino también con una propensión al tono sacro y la imitación estilístico-formal del Nuevo Testamento, aunque sin mimetismos rígidos. Esta variedad integrada de registros lingüísticos contribuye a dar verosimilitud a las antítesis de los mitos bíblicos presentes en el relato del mecanoscrito, los cuales conservan el primigenio sentido fundacional de las Escrituras aunque ofreciendo unos principios ideológicos alternativos al legado judeocristiano patriarcal. También la posición necesariamente subordinada de Dídac y la controversia sobre ciertos aspectos del feminismo matriarcal ligado al personaje de Alba (que Nilsson-Fernàndez [2018, p. 107] también pone en tela de juicio) debilitan el carácter revolucionario de la narración. Tal vez estas y otros fisuras del texto -no examinadas por la falta de espacio- hayan hecho inevitable el fracaso de una revolución con tanto potencial rupturista, un fracaso que se evidencia en el epílogo de la novela y que podría radicar incluso en la falta de autenticidad misma del relato en cuanto recreación de un mundo pasado. En el fondo, Mecanoscrito del segundo origen se puede interpretar como un gran grito contra la Historia en mayúscula, como una muestra de escapismo anti-histórico escrito, pues, adecuadamente según las pautas del género post-apocalíptico. Esta lectura tendría dos vertientes: por un lado, una generalista, es decir, la constatación de la imposibilidad de una coexistencia armónica entre los seres humanos a causa de su mentalidad y comportamiento naturales; por el otro, una mucho más concreta, circunscrita a la experiencia personal de Pedrolo, que vivió la derrota de la Cataluña republicana y sufrió la totalidad del franquismo, experiencias que le comportaron un profundo escepticismo, una inteligente mordacidad y, malgré tout, la necesidad de un sano escapismo crítico que se complementaba con un indomable resistencialismo.

\footnotetext{
${ }^{22}$ Maestre Brotons (2018, p. 33) también habla de la "desconfiança absoluta en la humanitat" que revela la novela, aunque este investigador desdibuja el adjetivo usado al poner como excepción a los personajes de Alba y Dídac.
} 


\section{BIBLIOGRAFÍA}

Bennasar, S. (2013). L'ocultació sistemàtica de Pedrolo. Jornades "Incidència: els moviments socials i els seus impactes" [Comunicación inédita]. Recuperado de https://www.upf.edu/ documents/3500770/3517420/bennasar.pdf/a451c331-ec71-4c3c-99a8-2546c4606916.

Bensoussan, M. (1988). Mecanoscrit del segon origen de Manuel de Pedrolo: una nova interpretació del mite del recomençament. Zeitschrift für Katalanistik, 1, 73-79.

Casciaro Ramírez, J.M. (1983). Exégesis biblica, hermenéutica y teología. Pamplona: Ediciones Universidad de Navarra.

Gallardo Torrano, P. (2018). Les bones intencions contra el futur incert: el Mecanoscrit de Manuel de Pedrolo i Los últimos días d'Àlex i David Pastor. En S. Martín Alegre (ed.), "Explorant" Mecanoscrit del segon origen: "Noves lectures" (57-84). Tarragona: Orciny Press.

Gregori, A. (2015). Mecanoscrit del segon origen Manuela de Pedrolo: echa mitów biblijnych w czasach postapokaliptycznych. En M. Loba, B. Łuczak \& A. Gregori (eds.), „Literatury mniejsze” Europy romańskiej, 2: Między historia a mitem (220-234). Poznań: Wydawnictwo Naukowe UAM.

Hernández Ripoll, J.M. (2001, 18 de enero). El triomf de l'espècie: relectura del Mecanoscrit del segon origen. Avui [supl. "Cultura"], p. VIII.

Lévi-Strauss, C. (1969). Las estructuras elementales del parentesco (M.T. Cevasco, trad.). Barcelona: Paidós.

Maestre Brotons, A. (2018). Mecanoscrit del segon origen: contracultura i política en els anys setanta. En S. Martín Alegre (ed.), "Explorant” Mecanoscrit del segon origen: "Noves lectures" (31-56). Tarragona: Orciny Press.

Martín Alegre, S. (2018a). Introducció. Manuel de Pedrolo, Mecanoscrit del segon origen i les paradoxes de la Literatura catalana. En S. Martín Alegre (ed.), "Explorant” Mecanoscrit del segon origen: "Noves lectures" (9-30). Tarragona: Orciny Press.

Martín Alegre, S. (2018b). Educant el Dídac: el nou pare de la humanitat i la fi del patriarcat a Mecanoscrit del segon origen. En S. Martín Alegre (ed.), "Explorant" Mecanoscrit del segon origen: "Noves lectures" (145-172). Tarragona: Orciny Press.

Martín Alegre, S. (ed.) (2017). Manuel de Pedrolo's Typescript of the Second Origin. Alambique: Revista académica de ciencia ficción y fantasía, 4 (2). Recuperado de https://scholarcom mons.usf.edu/alambique/vol4/iss2/.

Munné-Jordà, A. (2006). La ciència-ficció de Manuel de Pedrolo: més que el Mecanoscrit, però també. Recuperado de http://www.fundaciopedrolo.cat/articles/ciencia_ficcio_a_munne.pdf.

Muraro, L. (1994). El orden simbólico de la madre (B. Albertini, trad.). Madrid: horas y HORAS.

Nilsson-Fernàndez, P. (2018). Alba, mare, eterna: espais de violència i l' "Última Dona" a Mecanoscrit del segon origen. En S. Martín Alegre (ed.), "Explorant” Mecanoscrit del segon origen: "Noves lectures" (85-114). Tarragona: Orciny Press.

Pedrolo, M. de (1984). Mecanoscrit del segon origen (23a ed.). Barcelona: Ed. 62.

Pedrolo, M. de (2016). Mecanoscrit del segon origen / Mecanoscrito del segundo origen / Typescript of the second origin (D. Santos \& S. Martín Alegre, trad.). Lérida: Institut d'Estudis Ilerdencs.

Pedrolo, M. de (2018). Typescript of the second origin. Middeltown: Wesleyan University Press.

Santaulària Capdevila, I. (2018). Mecanoscrit del segon origen i ficcions distòpiques i postapocalíptiques contemporànies per a joves adults: anticipant una heroïna feminista? En S. Martín Alegre (ed.), "Explorant" Mecanoscrit del segon origen: "Noves lectures" (115-144). Tarragona: Orciny Press. 